\title{
Septic Shock Caused by Waterhouse-Friderichsen Syndrome Caused by Neisseria meningitidis
}

\author{
Takeshi Nishimura, Hiroyuki Sakata, Kunihiro Shirai, Hiroyuki Nakao, and Joji Kotani
}

\begin{abstract}
Background: Neisseria meningitidis is a rare but serious pathogen that leads to life-threatening septic shock. This infection can rapidly induce a critical condition.

Case 1: A 48-year-old male was transferred to our department with septic shock resulting from an unknown cause. A few days after admission, Neisseria meningitides was detected in his blood culture. Because catecholamine or massive transfusion could not support his vital signs, plasma exchange was introduced. He recovered and was discharged on post-admission day 96 without extremity amputation.

Case 2: A 42-year-old male presented with sudden-onset whole-body cyanosis and shock. Although he was treated with several medications, he died on post-admission day two. Neisseria meningitidis was detected in his blood culture.

Conclusion: Prompt recognition and rapid therapy, including plasma exchange, might have the potential to treat patients with this infection.
\end{abstract}

Keywords: Neisseria meningitidis; septic shock

$\mathbf{P}$ URPURA FULMINANS rarely occurs in adults but is seen in patients with meningococcal infections, which have a high mortality rate. Because of its rarity, prompt recognition and early indication of treatment is important.

We treated two critically ill patients with septic shock caused by Neisseria meningitidis. Based on early goal-directed therapy, massive transfusion and early antibiotic agents were administered soon after blood culture. Although one patient who underwent plasma exchange treatment survived and recovered without amputation of the distal extremities, the other patient did not survive beyond 40 hours. We believe that our report may assist emergency clinicians in recognizing the condition promptly leading to early treatment, including plasma exchange.

\section{Case 1}

A 48-year-old male was transferred to our hospital because of unstable vital signs with unknown cause. He was unconscious at presentation with purpura in his extremities; intuba- tion, massive transfusion, antibiotics (meropenem), a large amount of vasopressors, and continuous renal replacement therapy (CRRT) were administered quickly. His vital signs on arrival were as follows: heart rate, 140 beats per minute; blood pressure, $168 / 50 \mathrm{~mm} \mathrm{Hg}$; respiratory rate, 26 breaths per minute; body temperature, $40^{\circ} \mathrm{C}$. His laboratory data are shown in Table 1. His arterial blood gas tests were as follows: $\mathrm{pH}: 7.042$, $\mathrm{pCO}_{2}: 86.4 \mathrm{~mm} \mathrm{Hg}, \mathrm{pO}_{2}: 23.4 \mathrm{~mm} \mathrm{Hg}$, base excess (BE): $-8.4 \mathrm{mmol} / \mathrm{L}$; bicarbonate: $23.4 \mathrm{mmol} / \mathrm{L}$, glucose: $41 \mathrm{mg} / \mathrm{dL}$, and lactate level: $9.0 \mathrm{~mol} / \mathrm{L}$. Despite prompt therapy, his blood pressure deteriorated and his heart rate was worsened rapidly, followed by pulseless electric activity (PEA). After resuscitation with a few intervals of PEA, we decided to initiate plasma apheresis therapy because of refractory septic shock; his vital signs and laboratory data improved gradually. With tracheotomy, percutaneous endoscopic gastrostomy, and arteriovenous shunt because of acute kidney injury, he transferred to the rehabilitation hospital on post-admission day 96. Without amputation of his limbs, he recovered well and the purpura disappeared. His consciousness improved gradually. (See Fig. 1.)

Department of Emergency, Disaster, and Critical Care Medicine, Hyogo College of Medicine, Nishinomiya, Hyogo, Japan.

(C) Takeshi Nishimura et al. 2017; Published by Mary Ann Liebert, Inc. This Open Access article is distributed under the terms of the Creative Commons License (http://creativecommons.org/licenses/by/4.0), which permits unrestricted use, distribution, and reproduction in any medium, provided the original work is properly credited. 
Table 1. Laboratory Data for CASE 1

\begin{tabular}{|c|c|c|c|c|c|}
\hline Total protein & 6.2 & $\mathrm{~g} / \mathrm{dL}$ & WBC & 14190 & $/ \mathrm{mcL}$ \\
\hline Albumin & 3.4 & $\mathrm{~g} / \mathrm{dL}$ & $\mathrm{RBC}$ & $553 \times 10^{6}$ & $/ \mathrm{mcL}$ \\
\hline Total bilirubin & 2.4 & $\mathrm{mg} / \mathrm{dL}$ & HGB & 18.3 & $\mathrm{~g} / \mathrm{dL}$ \\
\hline $\mathrm{AST}$ & 218 & $\mathrm{U} / \mathrm{L}$ & $\mathrm{HCT}$ & 53.8 & $\%$ \\
\hline ALT & 107 & $\mathrm{U} / \mathrm{L}$ & PLT & $1.9 \times 10^{3}$ & $/ \mathrm{mcL}$ \\
\hline $\mathrm{LDH}$ & 853 & $\mathrm{U} / \mathrm{L}$ & & & \\
\hline ALP & 561 & $\mathrm{U} / \mathrm{L}$ & PT & $<10$ & $\%$ \\
\hline$\gamma$-GTP & 788 & $\mathrm{U} / \mathrm{L}$ & PT-INR & 5.77 & \\
\hline AMY & 626 & $\mathrm{U} / \mathrm{L}$ & APTT & $>180$ & second \\
\hline $\mathrm{CK}$ & 1985 & $\mathrm{U} / \mathrm{L}$ & Fib & $<50$ & $\mathrm{mg} / \mathrm{dL}$ \\
\hline BUN & 10.5 & $\mathrm{mg} / \mathrm{dL}$ & D-dimer & $>80$ & $\mathrm{ng} / \mathrm{mL}$ \\
\hline Cre & 3.78 & $\mathrm{mg} / \mathrm{dL}$ & AT-III & 44 & $\%$ \\
\hline $\mathrm{Na}$ & 146 & $\mathrm{mmol} / \mathrm{L}$ & & & \\
\hline $\mathrm{K}$ & 3.9 & $\mathrm{mmol} / \mathrm{L}$ & PCT & 1347 & $\mathrm{ng} / \mathrm{mL}$ \\
\hline CI & 104 & $\mathrm{mmol} / \mathrm{L}$ & $\mathrm{HbA}_{1 \mathrm{c}}$ & 5.6 & $\%$ \\
\hline $\mathrm{Ca}$ & 8.2 & $\mathrm{mg} / \mathrm{dL}$ & Pre-sepsin & 2330 & $\mathrm{pg} / \mathrm{mL}$ \\
\hline IP & 4.9 & $\mathrm{mg} / \mathrm{dL}$ & feritine & 4370 & $\mathrm{ng} / \mathrm{mL}$ \\
\hline CRP & 7.55 & $\mathrm{mg} / \mathrm{dl}$ & & & \\
\hline
\end{tabular}

$\mathrm{AST}=$ aspartate transaminase; $\mathrm{ALT}=$ alanine transaminase; $\mathrm{LDH}=$ lactate dehydrogenase; $\mathrm{ALP}=$ alkaline phosphatase; $\gamma$-GTP $=\gamma$ guanosine triphosphate; $\mathrm{AMY}=$ amylase; $\mathrm{CK}=$ creatine kinase; $\mathrm{BUN}=$ blood urea nitrogen; $\mathrm{Cre}=$ creatinine; $\mathrm{Na}=$ sodium; $\mathrm{K}=$ potassium; $\mathrm{CI}=$ chloride $\mathrm{Ca}=$ calcium; $\mathrm{IP}=; \mathrm{CRP}=\mathrm{C}$-reactive protein; $\mathrm{WBC}=$ white blood cell count $\mathrm{RBC}=$ red blood cell count $\mathrm{HGB}=$ hemoglobine; $\mathrm{HCT}=$ hematocrit; $\mathrm{Plt}=$ platelet; $\mathrm{PT}=$ prothrobin; $\mathrm{PT}-\mathrm{INR}=$; $\mathrm{APTT}=$ activated partial thromoplastin time; Fib = fibrinogen; AT-III $=$ angiotensin-III; PCT $=; \mathrm{HBA}_{1 \mathrm{c}}=$ hemoglogin $\mathrm{A}_{1 \mathrm{c}}$.

\section{Case 2}

A 42-year-old man presenting with whole-body cyanosis and shock was admitted to our emergency department. He had no notable medical history before admission. Because change of mental status and mottled skin were remarkable in the emergency department, intubation and massive crystalloid transfu- sion were administered. His vital signs on arrival were: heart rate, 130 beats per minute; blood pressure, $145 / 96 \mathrm{~mm} \mathrm{Hg}$; respiratory rate, 24 breaths per minutes; oxygen saturation, unmeasurable. His laboratory data were as follows: white blood cell count: 2,170 per microliter, hemoglobin: $17.2 \mathrm{~g} / \mathrm{dL}$, hematocrit: $49.1 \%$, platelets: $5.6 \times 10^{4}$ per microliter, prothrombin time: $39.6 \%$, D-dimer: $50.75 \mathrm{mcg} / \mathrm{mL}$. His arterial blood gas

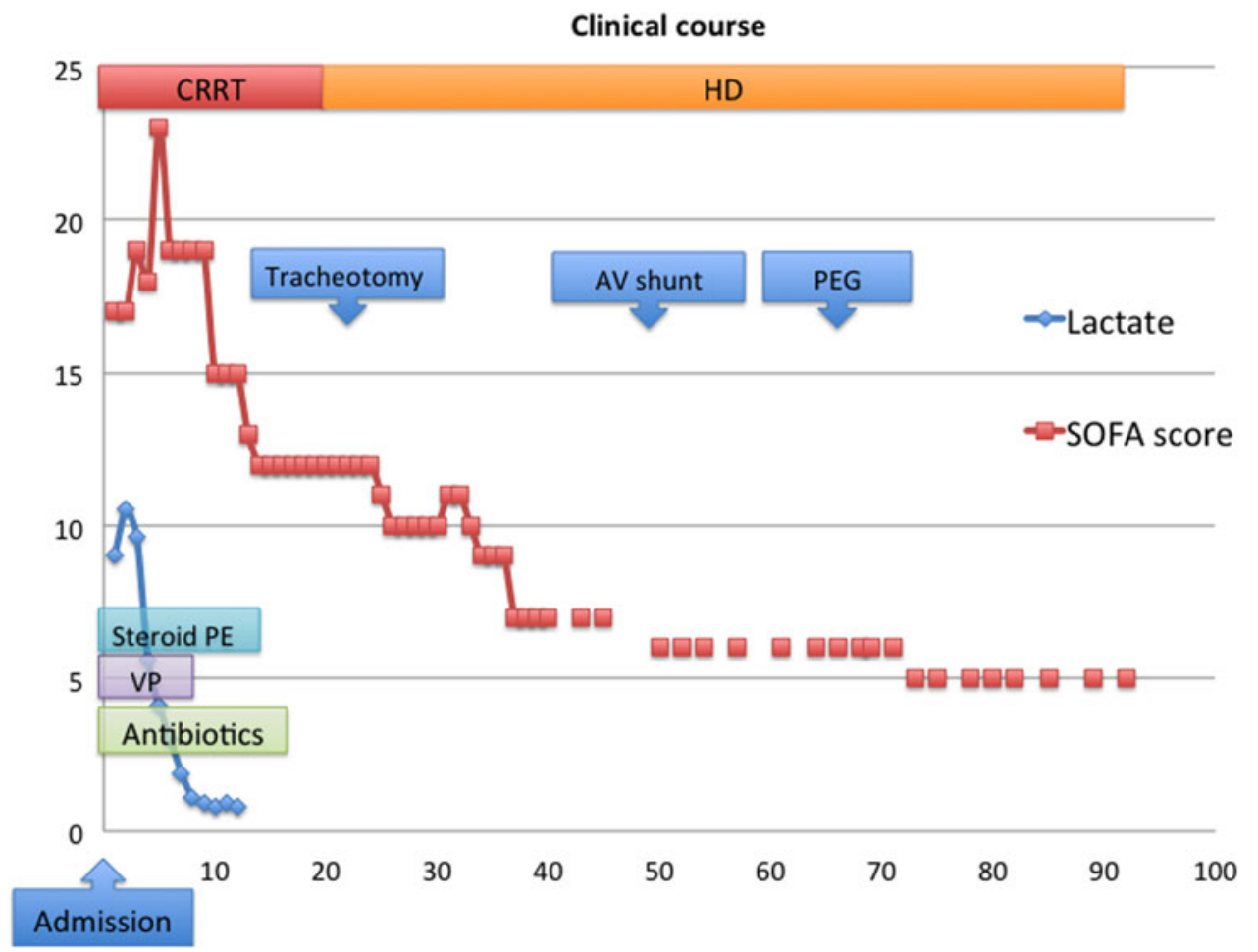

FIG. 1. Clinical course of case $1 . \mathrm{CRRT}=$ continuous renal replacement therapy; $\mathrm{HD}=$ hemodialysis; $\mathrm{AV}=$ arteriovenous; $\mathrm{PEG}=$ percutaneous endoscopic gastrostomy; $\mathrm{SOFA}=$ sequential organ failure assessment; $\mathrm{PE}=$ plasma exchange; $\mathrm{VP}=$ vasopressors. 
data were as follows: $\mathrm{pH}: 7.183, \mathrm{pcO}_{2}: 36.9 \mathrm{~mm} \mathrm{Hg}, \mathrm{po}_{2}$ : $94.2 \mathrm{~mm} \mathrm{Hg}$, bicarbonate: $13.3 \mathrm{mmol} / \mathrm{L}, \mathrm{BE}:-14.2 \mathrm{mmol} / \mathrm{L}$, and lactate level: $9.8 \mathrm{mmol} / \mathrm{L}$. Although antibiotics (meropenem and minocycline), recombinant thrombomodulline, anti-thrombin, vasopressor, and CRRT were administered quickly, purpura in the peripheral extremities and trunk worsened rapidly. The patient died within $40 \mathrm{~h}$ of hospitalization. Two days later, the patient's blood culture presented Neisseria meningitidis infection. Adrenal gland hemorrhage was identified in both cases in computed tomography (case 1) and morbid anatomy (case 2).

\section{Discussion}

Septic shock caused by Neisseria meningitidis infection, defined as Waterhouse-Friderichsen syndrome in 1946 [1], has a high mortality rate of between $21 \%$ and $44 \%$ [2]. Neisseria meningitidis cause a fulminating fatal infection, frequently with few or no signs or pre-conditions. The presenting clinical picture is frequently pharyngitis, fever, and gastrointestinal symptoms, which are non-specific symptoms, followed by rapid widespread petechiae and wholebody cyanosis. The progress of the condition in these cases is so rapid that commonly death occurs within 12 to $24 \mathrm{~h}$ after the appearance of the first symptom. Ferguson et al. [3] reviewed 16 meningococcal patients and reported that almost all had died within $48 \mathrm{~h}$.

A feature of systemic Neisseria meningitidis infection is rapid microvascular thrombosis in the peripheral extremities, called purpura fluminans. This symptom is provoked by bacterial lipopolysaccharide (LPS), which activates coagulation systems after inhibition of fibrinolysis. Hellum et al. [4] reported that tissue factor-bearing microparticles appear to contribute to the pathogenesis of this rapid disseminated intravascular coagulopathy [4]. Brandtzaeg et al. [5] demonstrated classification and pathogenesis of meningococcal infection. They reported the relation between plasma LPS level and fatality rate in patients with systemic meningococcal disease [5].

Adrenal hemorrhage is a most remarkable finding in Waterhouse-Friderichsen syndrome. Although the precise mechanism is obscure, the intrinsic vulnerability of hemorrhage is caused by anatomic factors. The adrenal gland is fragile to any increase of adrenal arterial and venous pressure after infections [6]. Neonates and pediatric patients are statistically at an increased risk for coagulopathy. [7]

Meningococcal septic shock occurs predominantly in young children and adolescents. In addition to the high mortality rate, amputation of digits or limbs may be necessary as a result of skin necrosis in patients who survive septic shock. Lindy et al. [8] reported long-term psychosocial outcomes in young adults who survived septic shock caused by Neisseria meningitides during childhood. They concluded that $5 \%-20 \%$ of the patients still struggle with ongoing problems associated with the past illness. (8)

In addition to children, human immunodeficiency virus (HIV)-positive patients should also receive Neisseria vaccinations. Agrawal et al. [9] described a case of a 34-year-old man who had sex with men in the United States presenting with acute fulminant meningococcemia. They recommended prompt recognition and expanding vaccinations against Neisseria meningitidis.
Neisseria meningitidis infection is more frequent in children [10]. Villa et al. [11] reported a multi-center prospective descriptive study of patients admitted to pediatric intensive care units for sepsis. In 136 patients, the most common etiology was Neisseria meningitides [11]. They concluded that patients with multiple organ failure, neutropenia, and purpura had a worse prognosis.

Hirono et al. [12] reviewed patients with meningococcemia without meningitis in Japan. Compared with other countries, the incidence of meningococcal infection and number of carriers in Japan is low, occurring in $0.4 \%[13,14]$.

It was demonstrated that poor prognosis of septic shock caused by Neisseria meningitidis is related to low protein C level [15,16]. Vaccarella et al. [17] described a case of an 18year-old male with meningococcal sepsis and purpura fulminans (17). Because protein $C$ and anti-thrombin levels were extremely low, replacement with protein $\mathrm{C}$ concentrates was begun, leading to uneventful discharge.

Protein $\mathrm{C}$ concentrate is not available commercially in Japan, therefore, institution of protein $\mathrm{C}$ concentrate was not possible with our cases. Based on this, we treated the patient in case 1 with plasma apheresis, but the patient in case 2 could not receive plasma apheresis because of acute deterioration of his vital signs. To our knowledge, no reports about the association between plasma apheresis and septic shock caused by Neisseria meningitides have been published. Plasma apheresis might be a key therapy when confronting septic shock patients with meningococcemia.

\section{Conclusion}

Neisseria meningitidis infection is a rare but serious illness, therefore, emergency clinicians should be aware of this unspecific condition. Early recognition and early treatment of purpura fulminans are necessary.

Based on our case reports and previous reports, plasma apheresis might have the potential to treat refractory septic shock caused by Neisseria meningitidis successfully. Further reports and evidence are needed.

\section{Acknowledgments}

Written informed consent was obtained from the patient's legal guardian(s) for the publication of these case reports and accompanying images.

T.N. designed this manuscript of this case report. H.S., K.S., and H.N. participated in the treatment of these patients. J.K. made a decision of final approve in this manuscript. All authors read and approved the final manuscript. H.S., K.S., and H.N. are clinicians. H.N. is an assistant professor at Hyogo College of Medicine. J.K. is a professor at Hyogo College of Medicine.

\section{Author Disclosure Statement}

All authors declare no conflict of interests.

\section{References}

1. Newcomb AL. Meningococcemia with WaterhouseFriederichsen syndrome. U S Nav Med Bull 1946;46:273.

2. Fourrier F, Lestavel P, Chopin C, et al. Meningococcemia and purpura fulminans in adults: Acute deficiencies of proteins $\mathrm{C}$ and $\mathrm{S}$ and early treatment with antithrombin III concentrates. Intensive Care Med 1990;16:121-124. 
3. Ferguson JH, Chapman OD. Fulminating meningococcic infections and the so-called Waterhouse-Friderichsen syndrome. Am J Pathol 1948;24:763-795.

4. Hellum M, Ovstebo R, Brusletto BS, et al. Microparticleassociated tissue factor activity correlates with plasma levels of bacterial lipopolysaccharides in meningococcal septic shock. Thromb Res 2014;133:507-514.

5. Brandtzaeg P, van Deuren M. Classification and pathogenesis of meningococcal infections. Meth Mol Biol 2012;799: 21-35.

6. Rao RH. Bilateral massive adrenal hemorrhage. Med Clin North Am 1995;79:107-129.

7. Varon J, Chen K, Sternbach GL. Rupert Waterhouse and Carl Friderichsen: Adrenal apoplexy. J Emerg Med 1998; 16:643-647.

8. Vermunt LC, Buysse CM, Joosten KF, et al. Survivors of septic shock caused by Neisseria meningitidis in childhood: Psychosocial outcomes in young adulthood. Pediatr Crit Care Med 2011;12:e302-309.

9. Agrawal A, Jasdanwala S, Agarwal A, Eng M. Fatal Waterhouse-Friderichsen syndrome due to serotype C Neisseria meningitidis in a young HIV negative MSM (men who have sex with men). BMJ Case Rep 2014;2014.

10. Betrosian AP, Berlet T, Agarwal B. Purpura fulminans in sepsis. Am J Med Sci 2006;332:339-345.

11. Vila Perez D, Jordan I, Esteban E, et al. Prognostic factors in pediatric sepsis study, from the Spanish Society of Pediatric Intensive Care. Pediatr Infect Dis J 2014;33:152-157.

12. Horino T, Kato T, Sato F, t al. Meningococcemia without meningitis in Japan. Intern Med 2008;47:1543-1547.

13. Tanaka H, Kuroki T, Watanabe $\mathrm{Y}$, et al. [Isolation of Neisseria meningitidis from healthy persons in Japan]. Kansenshogaku Zasshi 2005;79:527-533.

14. Stephens DS, Greenwood B, Brandtzaeg P. Epidemic meningitis, meningococcaemia, and Neisseria meningitidis. Lancet 2007;369:2196-2210.

15. Powars DR, Rogers ZR, Patch MJ, McGehee WG, Francis RB, Jr. Purpura fulminans in meningococcemia: Associa- tion with acquired deficiencies of proteins $\mathrm{C}$ and $\mathrm{S}$. N Engl J Med 1987;317:571-572.

16. Fijnvandraat K, Derkx B, Peters M, et al. Coagulation activation and tissue necrosis in meningococcal septic shock: Severely reduced protein $\mathrm{C}$ levels predict a high mortality. Thromb Hemost 1995;73:15-20.

17. Vaccarella G, Pelella R. Replacement treatment with protein $\mathrm{C}$ in an 18-year-old man with meningococcal sepsis and purpura fulminans. Minerva anestesiol 2003;69:691-693.

Address correspondence to: Dr. Takeshi Nishimura

Department of Emergency, Disaster, and Critical Care Medicine Hyogo College of Medicine 1-1 Mukogawa, Nishinomiya Hyogo 663-8501

Japan

E-mail: kogushi1@msn.com

$\begin{aligned} & \quad \text { Abbreviations Used } \\ & \mathrm{BE}=\text { base excess } \\ & \mathrm{CRRT}=\text { continuous renal replacement therapy } \\ & \mathrm{LPS}=\text { lipopolysaccharide } \\ & \mathrm{PEAS}=\text { pulseless electric activity } \\ & \mathrm{IV}=\text { intravenous } \\ & \mathrm{TPN}=\text { total parenteral nutrition }\end{aligned}$

Cite this article as: Nishimura T, Sakata H, Shirai K, Nakao H, Kotani J (2017) Septic shock caused by Waterhouse-Friderichsen syndrome caused by Neisseria meningitidis. Surgical Infections Case Reports 2:1, 5-8, DOI: $10.1089 /$ crsi.2016.0051 